arrhythmic drugs at present available have drawbacks, because in inhibiting ventricular tachyarrhythmias they also depress the myocardium, and their administration requires close and constant supervision. But one practical scheme which could be organized now with little trouble or expense would be to identify places of high risk-for example, factories employing large numbers of men aged over 45 . Resuscitation facilities on the spot, including training of first-aid staff, could join with those at the local hospital to form a life-saving service.

\section{Old People in Hospital}

The expectation of life at birth in England and Wales was 68 years for men and 75 for women in 1966, and comparable figures are to be found in many developed countries today. The figures mean that, on certain assumptions, half the babies born in 1966 are likely to reach the age of 68 if males and 75 if females. In the first decade of this century the expectation of life was about 50 years for males and females combined, and in the 1840 s it was about 40 years. $^{1}$ Thus, despite the striking testimony of some of the tombstones in country churchyards, old age is for the great majority of people an expectation of the middle of the twentieth century. For some a blessing, for others it brings all the familiar consequences of mental and physical enfeeblement. For the community as a whole it presents a problem still novel, illunderstood, and unsolved.

It is against this background rather than the acrimony it must have engendered that the book Sans Everything ${ }^{2}$ needs to be considered. It was published in June 1967 to the accompaniment of considerable publicity-being in fact reprinted before publication. Described as being " presented by Barbara Rabb on behalf of A.E.G.I.S." (Aid for the Elderly in Government Institutions), it contained in the first part charges of misconduct and even cruelty by the staff of hospitals towards the old people in their care, and in the second part chapters by various authors giving their proposals for improving the care of old people. As the book made serious claims on public attention it was not surprising that the Minister of Health set up independent committees of inquiry to examine its allegations. A White Paper containing the committees' reports was published on $9 \mathrm{July}^{3}$ and the same day the Minister announced in the House of Commons ${ }^{4}$ that they had found most of the allegations to be totally unfounded or grossly exaggerated. The committees also made some criticisms of the present conditions in hospitals and suggested how they might be improved.

The hospitals concerned and their staff have been cleared of imputations that should never have been made. And if

\footnotetext{
1 The Registrar General's Statistical Review of England and Wales for the Year 1966, Pt. 2, Tables, Population. 1968. H.M.S.O.

2 Sans Everything A Case to Answer, presented by Barbara Robb. 1967. London. See Brit. med. F., 1967, 3, 484.

- Findings and Recommendations Following Enquiries into Allegations Concerning the Care of Elderly Patients in Certain Hospitals, Cmnd. 3687. 1968. London.

- Brit. med. f., 1968, 3, 129.

- Brit. med. F. Suppl., 1968, 3, 13.

- Binks, F. A., Brit. med. F., 1968, 1, 269.

- Kay, D. W. K., Roth, M., and Hall, M. R. P., Brit. med. F., 1966, 2 967.

- Mezey, A. G., Hodkinson, H. M., and Evans, G. J., Brit. med. f., $1968,3,16$.
}

Sans Everything has served any useful purpose it is in displaying through the operation and reports of these committees of inquiry how devoted is the care given with but rare and regrettable exceptions to elderly people in hospital. But it would be most unfortunate if the publication of this book, containing, to use the Minister of Health's words, "so many allegations which are now authoritatively discredited," should obscure the deplorable hospital facilities with which valiant staffs are trying up and down the country to provide satisfactory care and treatment of their patients.

The community in general have not yet recognized the enormous problems confronting the Health Service as a simple consequence of increasing survival to old age. The Representative Body at Eastbourne ${ }^{5}$ drew attention to the lack of adequate finance for proper care. But since decisions will always have to be taken on the allocation of what resources are available, the medical profession has a duty to examine carefully the competing claims of patients with acute and chronic diseases on hospital beds. The idea of a patient "blocking a bed" in hospital can cover serious misconceptions about the purposes of hospitals, as F. A. Binks ${ }^{6}$ has recently made plain in a moving account of how some aged patients were mismanaged with the best of intentions. Though surveys continue to be made on the needs of the aged sick and reports to appear on their care and management, ${ }^{78}$ the sordid conditions in which many are condemned to live out their days in hospital are a disgrace to the nation.

\section{Insecticides in Man}

Organically bound chlorine is present in many of the most widely used and effective insecticides such as dicophane (D.D.T.) and dieldrin. Unlike the other commonly used insecticides, such as the organophosphorus anticholinesterase compounds, D.D.T. and dieldrin are chemically stable and are only slowly degraded biologically. Thus they may persist both in the general environment and within the human body.

In the B.M.F. this week (p. 146) Dr. D. C. Abbott, Dr. R. Goulding, and Mr. J. O'G. Tatton give the results of their analyses of fat taken from 247 necropsies carried out between 1965 and 1967 in England, Scotland, and Wales. This is a sequel to an earlier study reported in this journal. ${ }^{1}$ The levels of D.D.T., dieldrin, and benzene hexachloride (B.H.C.), in the body fat at any one time reflect the level of intake over the preceding period. ${ }^{2}$ These compounds do not accumulate remorselessly in our fat; the amount there represents a balance between the daily intake and daily excretion after metabolism. Recent refinements of the techniques of measuring these organochlorine insecticides make it possible to measure the very low levels in the blood. ${ }^{34}$ This may prove to be a better method for obtaining an accurate picture of the exposure of a population at any particular time. Clearly the state of health and degree of emaciation preceding death may distort the picture when data are obtained from necropsy material. Dr. Abbott and his colleagues point out the levels of these insecticides in our fat show a fall since the earlier survey, ${ }^{1}$ and since the main source of D.D.T. is our food they hope that this fall may be linked with the tendency to reduce the amounts of these insecticides that are used. However, W. F. Durham and colleagues ${ }^{2}$ found a lower concentration 
of D.D.T. in human food in the U.S.A. despite the fact that its use in agriculture had shown no downward trend. It seems probable that D.D.T. may be used more intelligently, so that food becomes less contaminated. Though attempts are being made to reduce the use of these persistent organochlorine insecticides, ${ }^{5}$ it is uncertain how far action taken in Britain can affect the levels in our food, for much of the animal products containing the D.D.T. is imported. Details are given by $\mathrm{H}$. Egan ${ }^{6}$ in an informative article, and data from prepared meals are available. ${ }^{7}$

The main concern of the medical profession is whether the presence of these small amounts of D.D.T. and dieldrin are harmful. W. J. Hayes ${ }^{8}$ has clearly presented and carefully evaluated the evidence, and he concludes that from our experience of twenty years' use there is no evidence that D.D.T. can injure people, even those who are much more heavily exposed than are the general population. People occupationally exposed to it have far higher levels in their fat, and they excrete much greater quantities of D.D.T. metabolites. The importance of studying the most heavily exposed populations has been emphasized by a World Health Organization Expert Committee. ${ }^{9}$ It is hoped that no time will be lost in setting up a prospective survey of those groups inevitably and heavily exposed to D.D.T. during its application in the W.H.O. malaria eradication programme. Some studies on mice ${ }^{10}$ suggest that exposure to low levels of D.D.T. continuously may have adverse effects on the third and fourth generation, and Dr. Abbott and his colleagues have shown that man is indeed exposed from the womb to the tomb. The studies on mice are to be repeated in several centres working under the auspices of the International Cancer Research Centre in Lyons, and it is as well to suspend judgement on the long-term hazards presented by D.D.T.

To try to put the toxic hazards in perspective, it is perhaps helpful to bear in mind that any member of the general population not occupationally exposed to either compound will each day ingest on average $0.33 \mathrm{mg}$. of lead but only $0.02 \mathrm{mg}$. of D.D.T., and in his blood there will be more than 30 atoms of lead for every molecule of D.D.T. Everyone has heard of chronic lead poisoning in people occupationally exposed to the metal, but chronic D.D.T. poisoning has not yet been described even in men receiving each day over one thousand times the amount of D.D.T. taken in by the general population. ${ }^{8}$

No one doubts the wisdom of trying to reduce the contamination of the environment by biologically active chemicals that persist long after the period of their effective action has passed. Such persistence may, among other things, encourage the emergence of resistant strains from otherwise sensitive populations of the target pest. Recent events have highlighted the human tragedies from the effects of resistant microorganisms appearing after the unintelligent use of antibiotics, and a committee has now been set up to look into the

1 Egan, H., Goulding, R., Roburn, J., and Tatton, J. O'G., Brit. med. F., 1965, 2, 66.

Durham, W. F., Armstrong, J. F., and Quinby, G. E., Arch. environm. Hlth, 1965, i1, 641 .

Robinson, J., and Hunter, C. G., Arch. environm. Hlth, 1966, 13, 558.

Dale, W. E., Curley, A., and Hayes, W. J., Industr. Med. Surg., 1967, 36, 275.

Ministry of Agriculture, Fisheries, and Food, Review of the Persistent Organochlorine Pesticides, 1964. H.M.S.O.

- Egan, H., Chem. and Industr., 1967, p. 1721.

- Egan, H., Chem. and Industr., 1967, p. 1721.

: Robinson, J., and McGill, A. E. J., Nature (Lond),

- Wld Hlth Org. techn. Rep. Ser., No. 356, 1967. Geneva.

10 Kemény, T., and Tarián, R., Experientia (Basel), 1966, 22, 748

1 Brit. med. $\ddot{\xi}$., 1968, 2, 709 . problem. ${ }^{11}$ Already several committees have reported on the use of insecticides that have never killed anyone in this country. It seems possible that a preoccupation with hypothetical hazards to man from insecticides has attracted more attention than the real hazards arising from an unwise use of antibiotics.

\section{Cancer in Childhood}

Children suffering from malignant diseases are rare in any one doctor's experience, but the total number of such children is by no means small. Tumours (including leukaemia) are the greatest single cause of death from disease between the ages of 1 and 15 in the United States, ${ }^{1}$ and in England and Wales the findings are similar ${ }^{2}$-in 1965 of 5,221 deaths in this age period neoplasms were responsible for 848 , respiratory disease was the next commonest cause with 820 deaths, and congenital malformations third with 573.

Children with neoplasms pose many problems, therapeutic, personal, psychological, parental (and indeed family), and many people are affected. There is no doubt that intensive studies in paediatric oncology are urgently needed in Britain if results are to be improved. J. K. Steward ${ }^{3}$ has repeatedly urged the need for the team approach. There must be centres for research and special treatment if there is to be progress, and for obvious reasons there cannot be many; they are expensive, for they require paediatric oncologists and a supporting team, including surgeons, pathologists, and radiotherapists. In justification of such a proposal it is evident that more progress has been made in centres where paediatric oncology has already developed (particularly in the U.S.A., but also in other countries, such as Australia and France) than in Britain.

The effects of cancer on the individual child-the number of different specialists he has to see, the repeated hospital admissions and separations from the family, and eventually his knowledge of his impending death-have all received too little attention. It was therefore timely that a conference on the care of the child with cancer was held in November 1966 in Seattle, ${ }^{4}$ the objects of which were to discuss how care should be organized, particularly the psychosocial aspects, and how children's cancer clinics should be run.

Among the interesting and valuable papers $M$. Green discussed the management of the child with a fatal illness and how he reacts and how he can be helped to cope without being psychologically overwhelmed. In addition to giving competent conscientious care the physician must be readily available to the child and his family at any hour of day or night, with clear arrangements for cover by a colleague. Continuous personal care by one doctor is vital for morale. Green also emphasized the need for more systematic investigation into the child's psychological reactions to his dying and how he expressed the knowledge or sense that he was dying.

Care of the family of the child with cancer was also discussed. Parental adjustment is achieved in most cases by

\footnotetext{
1 Bergman, A. B., and Schulte, C. J. A., Pediatrics, 1967, 40, 487.

- Registrar General's Statistical Review of England and ales for 1965, Part 1, Tables Medical.

Steward, J. K., Brit. med. 7., 1966, 1, 767.

- Pediatrics, 1967, 40, Suppl. No. 3. Part II.
} 